
\title{
25 Research Square \\ Thymosin Beta 4 as an Early Biomarker in Sepsis Induced Acute Kidney Injury
}

Jiahao Zhang

Wuhan University Zhongnan Hospital

Minghui Long

Wuhan University Zhongnan Hospital

Zhongyi Sun

Wuhan University Zhongnan Hospital

Cheng Yang

Wuhan University Zhongnan Hospital

Xiaofang Jiang

Wuhan University Zhongnan Hospital

Li He

Wuhan University Zhongnan Hospital

Lianjiu Su

Wuhan University Zhongnan Hospital

Zhiyong Peng ( $\sim$ Pengzy5@hotmail.com )

Wuhan University Zhongnan Hospital https://orcid.org/0000-0002-3873-9607

\section{Research}

Keywords: thymosin beta-4, acute kidney injury, biomarker, sepsis

Posted Date: May 11th, 2021

DOI: https://doi.org/10.21203/rs.3.rs-486278/v1

License: (c) (i) This work is licensed under a Creative Commons Attribution 4.0 International License.

Read Full License 


\section{Abstract}

Background: The incidence of sepsis is high among patients in the intensive care units (ICU) and acute kidney injury (AKI) is a common complication of sepsis that contributes to increased mortality. Thymosin beta-4 (TR4) is an actin-sequestering protein that can prevent inflammation and fibrosis in several tissues. However, its functions in septic AKI remain unknown.

Methods: 98 consecutive hospitalized patients with confirmed sepsis were enrolled. Demographics, comorbidities, laboratory findings, and outcomes were collected and analyzed. Serum T $\beta 4$ levels at ICU admission were measured and analyzed for evaluating the probability of AKI using the logistic regression. In addition, the effects of exogenous T $\beta 4$ on kidney injury was also conducted in mice where a sepsis model was induced by lipopolysaccharide (LPS) intraperitoneal injection.

Results: Of the 98 patients with sepsis, 47 (48\%) developed AKI. Patients with hypertension, diabetes, higher body mass index (BMI) and Sequential Organ Failure Assessment (SOFA) score were more likely to develop AKI. Among patients with AKI, hemoglobin, and T $\beta 4$ were significantly decreased. Multivariate analysis showed decreased T $\beta 4$, high SOFA, and high BMI to be independent risk factors for AKI in patients with sepsis. The overall mortality rate of the 98 septic patients was $20.4 \%$, and the mortality rate of those with AKI was $29.8 \%$. Kaplan-Meier analysis demonstrated that patients with AKI had a significantly higher risk of death. In particular, increasing AKI severity was associated with an increased risk of death. Furthermore, exogenous T $\beta 4$ could reduce renal apoptosis and attenuated renal dysfunction, as well as reducing systemic inflammatory response through the prevention of the activation of NF-KB pathway in the sepsis model.

Conclusions: The combination of T $\beta 4$, SOFA, and BMI could allow for timely detection of septic AKI. Exogenous $T \beta 4$ could prevent kidney injury in sepsis.

\section{Introduction}

Sepsis is a systemic inflammatory response syndrome (SIRS) that is caused by infection[1] and is one of the leading causes of death in intensive care unit (ICU) patients[2]. Acute kidney injury (AKI) is a series of pathophysiological changes caused by the sudden decline of renal function and the inability to exclude metabolic waste from the body, which is one of the most common complications of sepsis[3]. In the ICU, almost $50 \%$ of sepsis patients will develop AKI, thereby increasing the mortality rate of sepsis patients by $30-50 \%[4]$. Up to now, the updates of diagnosis and treatment of septic AKI remain quite limited[5]. The traditional diagnostic criteria based on creatinine and urine volume are lack of sensitivity, and the damage of renal function may occur earlier than the changes of conventional markers[6]. In survival patients with septic $A K I$, almost $70 \%$ of the patients progress to chronic kidney disease and renal failure, which results in poor prognosis[7]. There is therefore an urgent clinical need for novel biomarkers for the timely diagnosis and detection of septic AKI in its early stages. 
Thymosin beta-4 (Tß4) is a natural peptide encoded by the TMSB4X gene on the X-chromosome. It has been proven that $T \beta 4$ regulates a series of cellular functions that include cell motility, differentiation, apoptosis, angiogenesis, anti-inflammatory, and fibrosis[8]. T $\beta 4$ has attracted significant attention in the regenerative medicine field[9]. T $\beta 4$ promotes the regeneration of eyes, skin, heart, and other tissues[1013]. As an immune regulatory molecule, $T \beta 4$ has the ability to reduce oxidative stress and block the secretion of inflammatory cytokines in many disease models[14]. In addition, the ratio of G-actin and Factin, which are closely regulated by $T \beta 4$, has proven to be significantly different in patients with septic shock[15].

$\mathrm{T} \beta 4$ has not yet been investigated as a potential biomarker for septic AKI. Thus, this study explores the relationship between T $\beta 4$ and septic AKI in ICU patients, and evaluates the efficacy of exogenous T $\beta 4$ against septic AKI in mice.

\section{Materials And Methods}

\subsection{Observation study in patients with sepsis 2.1.1 Study design and participants}

This study was a prospective observational research study performed in a 58-bed closed intensive care unit of a 3300-bed tertiary center. With the approval of the Ethics Committee at Zhongnan Hospital of Wuhan University, patients in the ICU diagnosed with sepsis between January 1st and June 30th, 2019 were enrolled in the study. Patients with pre-existing AKI, chronic kidney disease, renal replacement therapy, end-stage renal disease, and organ transplantation were all excluded from the study. Patients who were aged below 18 or over 80 years old, and those who did not complete the consent form were also excluded.

\subsubsection{Data collection}

Upon the ICU admission with diagnosis of sepsis, patients' relevant information, including demographics, laboratory findings, management or treatment strategies, and outcomes were recorded. Blood and urine samples were obtained as soon as possible. Blood samples were centrifuged at $1500 \mathrm{~g}$ for $10 \mathrm{~min}$, while urine samples were centrifuged at $500 \mathrm{~g}$ for $10 \mathrm{~min}$; both were stored at $-80^{\circ} \mathrm{C}$ for analysis.

\subsubsection{AKI diagnostic criteria}

According to the diagnostic criteria of Kidney Disease Improving Global Outcomes (KDIGO)[16], AKI can be diagnosed if it meets one of the following criteria: an increase in serum creatinine by $\geq 0.3 \mathrm{mg} / \mathrm{dl}$ ( $\geq$ $26.5 \mu \mathrm{mol} / \mathrm{l}$ ) within $48 \mathrm{~h}$; an increase in serum creatinine to $\geq 1.5$ times baseline within the previous 7 days; urine volume $\leq 0.5 \mathrm{ml} / \mathrm{kg} / \mathrm{h}$ for $6 \mathrm{~h}$. AKI stage 1 is defined by an increase in serum creatinine of $50 \%-100 \%$ within 7 days or to $26.5 \mu \mathrm{mol} / \mathrm{L}$ or even greater than baseline within 48 hours, or urine output less than $0.5 \mathrm{ml} / \mathrm{kg} / \mathrm{h}$ for $6-12 \mathrm{~h}$; AKI stage 2 is defined by an increase of serum creatinine in $100 \%-200 \%$ from baseline, or urine output less than $0.5 \mathrm{ml} / \mathrm{kg} / \mathrm{h}$ for more than $12 \mathrm{~h}$; AKI stage 3 is defined by a an 
increase of $200 \%$ or more in serum creatinine, an increase to $353.6 \mu \mathrm{mol} / \mathrm{L}$ or more, urine output less than $0.3 \mathrm{ml} / \mathrm{kg} / \mathrm{h}$ for more than $24 \mathrm{~h}$ or anuria for more than $12 \mathrm{~h}$, or initiation of renal replacement therapy.

\subsection{Study on septic AKI in mice 2.2.1 Animal model of septic AKI}

All experiments were performed in accordance with Chinese legislation on the use and care of laboratory animals and were approved by the Animal Care and Use Committee of Wuhan University.

Male C57BL/ 6 mice weighing between 18 and $22 \mathrm{~g}$ were obtained from the Animal Center of Wuhan University. A sepsis model was created by injecting lipopolysaccharide (LPS, Sigma Chemical, St.Louis, Mo, USA) at the dose of $10 \mathrm{mg} / \mathrm{kg}$ intraperitoneally. Mice in the LPS $+T \beta 4$ group were pretreated with a $T \beta 4$ solution $(10 \mathrm{mg} / \mathrm{kg}$ ) via abdominal injection 15 minutes prior to LPS administration. Mice in the normal control (NC) group were only treated with saline. 24 hours after injection, blood was collected by intracardiac puncture. Heparinized blood was centrifuged for $10 \mathrm{~min}$ to separate the plasma. Kidneys were harvested for tissue analysis, and half of the harvested kidneys were fixed in $4 \%$ paraformaldehyde and processed for hematoxylin and eosin (H\&E)-stained analysis, while the other half were snap-frozen in liquid nitrogen and stored at $-80^{\circ} \mathrm{C}$ for protein analysis.

\subsubsection{Western blot analysis}

Total protein was extracted from the kidney tissue of mice. Equal amounts of proteins were separated using sodium dodecyl sulfate polyacrylamide gel electrophoresis (SDS-PAGE) and then transferred to a nitrocellulose membrane (Millipore). Following blocking with 5\% non-fat milk, the membrane was incubated with anti-T-P65 (1:1000, Proteintech, 10745-1-AP), P-P65 (1:1000, Bioswamp, PAB36317-P), TIKBa (1:1000, Bioswamp, PAB43967), P-IKBa (1:1000, Bioswamp, PAB43574-P), BCL2 (1:2000, Proteintech, 12789-1-AP), Caspase-3 (1:500, Proteintech, 19677-1-AP), or anti-GAPDH (1:5000, Bioswamp, PAB45851).

\subsubsection{Enzyme linked immunosorbent assay}

The concentration of human T $\beta 4$ were determined by commercially available ELISA kits (Jymbio, Colorful Gene Biological Technology Co. Ltd., Wuhan, China) according to the manufacturer's instructions. Mice serum cytokines interleukin-1 $\beta$ (IL-1 $\beta$ ), interleukin-6 (IL-6), and tumor necrosis factor-a (TNF- $\alpha$ ) were measured by commercial ELISA kits (Jymbio, Colorful Gene Biological Technology Co. Ltd., Wuhan, China). All samples were measured in triplicate.

\subsubsection{TUNEL assay}

In order to detect TUNEL-positive cells, an ApopTag Peroxidase In Situ Apoptosis Detection Kit was used in accordance with the manufacturer's instructions (S7100; Serologicals, Millipore).

\subsection{Statistical analysis}


All numerical data was expressed as mean \pm standard error or median and interquartile range.

Independent sample t-tests and Mann Whitney $\mathrm{U}$ tests were used to compare the continuous variables. In order to determine the discriminative power of T $\beta 4$, Sequential Organ Failure Assessment (SOFA), and body mass index (BMI) for septic AKI occurrence, receiver-operating characteristic (ROC) curves were constructed and the area under the curve (AUC) was determined with its $95 \%$ confidence interval (Cl). Statistical analyses were performed using Statistical Package for the Social Sciences (version 22.0) and GraphPad Prism software (version 8.0). P< 0.05 was considered to be statistically significant.

\section{Results}

\subsection{Characteristics of the Patients}

98 patients were enrolled in this study, whereby 47 (48\%) developed AKI (Table 1). In addition, 22 patients of them (46.8\%) complicated with AKI stage 1, 11 patients (23.4\%) AKI stage 2, and 14 patients $(29.8 \%)$ AKI stage 3 (Supplementary table 1 ). 
Table 1

Characteristics of the Patients with Sepsis Between NAKI and AKI

\begin{tabular}{|c|c|c|c|c|}
\hline Factors & All $(n=47)$ & $\begin{array}{l}\text { Survivors }(n= \\
33)\end{array}$ & $\begin{array}{l}\text { Non-survivors ( } \\
=14)\end{array}$ & $\begin{array}{l}P \\
\text { value }\end{array}$ \\
\hline Stage of AKI & & & & 0.020 \\
\hline AKI stage 1 & $22(46.8)$ & $19(57.6)$ & $3(21.4)$ & \\
\hline AKI stage 2 & $11(23.4)$ & $8(24.2)$ & $3(21.4)$ & \\
\hline AKI stage 3 & $14(29.8)$ & $6(18.2)$ & $8(57.1)$ & \\
\hline \multicolumn{5}{|l|}{ Treatment n(\%) } \\
\hline Mechanical ventilation & $24(51.1)$ & 11(33.3) & 13(92.9) & $\varangle 0.001$ \\
\hline Vasopressor & $33(70.2)$ & $20(60.6)$ & 13(92.9) & 0.027 \\
\hline Diuretic & $38(80.9)$ & $27(81.8)$ & 11(78.6) & 0.796 \\
\hline Renal replacement therapy & $9(19.1)$ & $6(18.2)$ & $3(21.4)$ & 0.796 \\
\hline Factors & All $(n=98)$ & $\operatorname{NAKI}(n=51)$ & AKI $(n=47)$ & $\begin{array}{l}P \\
\text { value }\end{array}$ \\
\hline Age (IQR) & $63(51-71)$ & $63(49-71)$ & $63(52-73)$ & 0.790 \\
\hline \multicolumn{5}{|l|}{ Gender $n(\%)$} \\
\hline Male & $63(64.3)$ & $34(66.7)$ & $29(61.7)$ & 0.608 \\
\hline Female & $35(35.7)$ & 17(33.3) & 18(38.3) & 0.608 \\
\hline \multicolumn{5}{|l|}{ Comorbidities n(\%) } \\
\hline Hypertension & $43(43.9)$ & 16(31.4) & $27(57.4)$ & 0.009 \\
\hline Diabetes & 18(18.4) & $5(9.8)$ & $13(27.7)$ & 0.023 \\
\hline Cardiovascular disease & $20(20.4)$ & 7(13.7) & 13(27.7) & 0.087 \\
\hline Cerebrovascular disease & 19(19.4) & 10(19.6) & $9(19.1)$ & 0.954 \\
\hline $\begin{array}{l}\text { Chronic obstructive pulmonary } \\
\text { disease }\end{array}$ & $8(8.2)$ & $4(7.8)$ & $4(8.5)$ & 0.904 \\
\hline Malignancy & $22(22.4)$ & $11(21.6)$ & $11(23.4)$ & 0.828 \\
\hline Body mass index (IQR) & $\begin{array}{l}22.49(20.35- \\
24.50)\end{array}$ & $\begin{array}{l}21.10(19.38- \\
23.44)\end{array}$ & $\begin{array}{l}23.03(21.81- \\
25.74)\end{array}$ & 0.002 \\
\hline $\begin{array}{l}\text { Sequential Organ Failure } \\
\text { Assessment (IQR) }\end{array}$ & $6(5-9)$ & $6(4-7)$ & $9(6-11)$ & $\varangle 0.001$ \\
\hline
\end{tabular}

* Only 78 survival patients were collected and analyzed. 


\begin{tabular}{|c|c|c|c|c|}
\hline Factors & All $(n=47)$ & $\begin{array}{l}\text { Survivors }(n= \\
\text { 33) }\end{array}$ & $\begin{array}{l}\text { Non-survivors ( } \\
=14 \text { ) }\end{array}$ & $\begin{array}{l}P \\
\text { value }\end{array}$ \\
\hline \multicolumn{5}{|l|}{ Laboratory data } \\
\hline $\begin{array}{l}\text { White blood cell count, } \times 109 / \mathrm{L} \\
(\text { IQR) }\end{array}$ & $\begin{array}{l}12.11(7.24- \\
17.77)\end{array}$ & $\begin{array}{l}11.42(7.14- \\
15.00)\end{array}$ & $\begin{array}{l}13.28(7.87- \\
20.18)\end{array}$ & 0.099 \\
\hline Neutrophil count, ×109/L (IQR) & $\begin{array}{l}10.63(5.92- \\
14.32)\end{array}$ & $\begin{array}{l}10.26(5.84- \\
13.72)\end{array}$ & $\begin{array}{l}11.19(6.03- \\
17.76)\end{array}$ & 0.198 \\
\hline Lymphocyte count, ×109/L (IQR) & $\begin{array}{l}1.18(0.73- \\
1.73)\end{array}$ & $\begin{array}{l}1.23(0.74- \\
1.81)\end{array}$ & $1.08(0.72-1.63)$ & 0.378 \\
\hline Platelet count, ×109/L (IQR) & $\begin{array}{l}133.0(84.3- \\
174.8)\end{array}$ & $\begin{array}{l}135.0(93.0- \\
163.0)\end{array}$ & 109(77.0-202.0) & 0.817 \\
\hline Hemoglobin g/L (IQR) & $\begin{array}{l}103.8(86.5- \\
123.9)\end{array}$ & $\begin{array}{l}109.0(95.0- \\
127.5)\end{array}$ & $\begin{array}{l}99.5(79.5- \\
116.0)\end{array}$ & 0.046 \\
\hline $\begin{array}{l}\text { Alanine aminotransferase, } \mathrm{U} / \mathrm{L} \\
\text { (IQR) }\end{array}$ & $31.5(18.0-78.7)$ & $\begin{array}{l}32.0(18.0- \\
88.0)\end{array}$ & $31.0(18.0-77.0)$ & 0.787 \\
\hline $\begin{array}{l}\text { Aspartate aminotransferase, } \mathrm{U} / \mathrm{L} \\
\text { (IQR) }\end{array}$ & $\begin{array}{l}51.0(31.2- \\
101.7)\end{array}$ & $\begin{array}{l}49.0(32.0- \\
91.0)\end{array}$ & $56.0(29.0-158.0)$ & 0.481 \\
\hline Abumin, g/L (IQR) & $\begin{array}{l}27.7(24.4- \\
30.8)\end{array}$ & $\begin{array}{l}27.6(23.8- \\
30.3)\end{array}$ & $27.8(24.9-32.0)$ & 0.325 \\
\hline 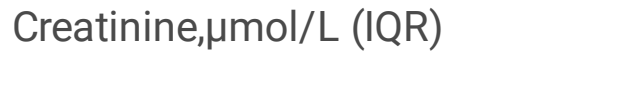 & $\begin{array}{l}68.8(56.6- \\
84.8)\end{array}$ & $\begin{array}{l}67.0(53.1- \\
81.7)\end{array}$ & $70.1(58.8-85.65)$ & 0.260 \\
\hline Urea, mmol/L (IQR) & $\begin{array}{l}6.42(5.40- \\
7.70)\end{array}$ & $\begin{array}{l}5.81(5.10- \\
7.72)\end{array}$ & $6.76(5.90-7.30)$ & 0.051 \\
\hline Procalcitonin, ug/L (IQR) & $\begin{array}{l}8.47(1.95- \\
51.27)\end{array}$ & $\begin{array}{l}6.54(2.90- \\
29.34)\end{array}$ & $\begin{array}{l}10.33(1.22- \\
65.33)\end{array}$ & 0.136 \\
\hline Lactic acid, mmol/L (IQR) & $\begin{array}{l}2.40(1.20- \\
3.80)\end{array}$ & $\begin{array}{l}2.10(0.95- \\
3.25)\end{array}$ & $2.80(1.50-5.80)$ & 0.077 \\
\hline Thymosin beta 4, ng/ml (IQR) & $\begin{array}{l}4.41(1.65- \\
9.74)\end{array}$ & $\begin{array}{l}7.23(3.32- \\
113.28)\end{array}$ & $2.03(1.29-4.91)$ & $\nabla 0.001$ \\
\hline \multicolumn{5}{|l|}{ Outcome } \\
\hline Death n(\%) & $20(20.4)$ & $6(11.8)$ & $14(29.8)$ & 0.027 \\
\hline ICU stay (IQR)* & $5(3-7)$ & $4(2-7)$ & $5(4-8)$ & 0.023 \\
\hline Hospital stay (IQR)* & $12(9-14)$ & $11(9-14)$ & $12(10-16)$ & 0.049 \\
\hline
\end{tabular}

There was no significant difference in age and gender between the AKI and non-AKI. However, patients with hypertension and diabetes had a greater likelihood of developing AKI. In particular, patients with a 
high BMI and SOFA score were more likely of developing AKI. Besides, the hemoglobin and T $\beta 4$ in patients with AKI were significantly decreased.

\subsection{Outcome of patients in sepsis with or without AKI}

Of the 98 patients included in this study, 78 were discharged and 20 died. The overall mortality rate was $20.4 \%$, with $29.8 \%$ in AKI and $11.8 \%$ in non-AKI (Table 1). Kaplan-Meier survival curve showed that the survival rate in the AKI was lower than that in non-AKI $(P=0.032)$ (Fig. 1. A). Cox proportional hazard regression also revealed that the hazard ratio of $\mathrm{AKI}$ to mortality was 2.674 with $95 \% \mathrm{Cl}$ (1.027-6.960, $\mathrm{P}$ $=0.044)$. Furthermore, the ICU stay and hospital stay for patients with septic AKI was significantly increased (Table 1).

In addition, increasing AKI severity was associated with increased mortality (Table 2 and Fig. 1. B). Of the 47 patients with septic AKI, 24 (51.1\%) received mechanical ventilation, 33 (70.2\%) received vasopressor, $38(80.9 \%)$ received diuretics, and $9(19.1 \%)$ received renal replacement therapy (Supplementary table 1$)$.

Table 2

Multivariate analysis of independent risk factors of Septic AKI

\begin{tabular}{|lllll|}
\hline Factor & OR(95\% Cl) & P value & Adjust OR(95\% Cl) & P value \\
\hline T $\beta 4$ & $0.869(0.800-0.945)$ & 0.001 & $0.872(0.792-0.961)$ & 0.006 \\
\hline SOFA & $1.321(1.134-1.537)$ & $\nabla 0.001$ & $1.392(1.155-1.676)$ & 0.001 \\
\hline BMI & $1.257(1.084-1.458)$ & 0.003 & $1.227(1.009-1.491)$ & 0.040 \\
\hline Hypertension & $2.953(1.291-6.753)$ & 0.009 & - & 0.326 \\
\hline Diabetes & $3.518(1.145-10.809)$ & 0.023 & - & 0.077 \\
\hline Hemoglobin & $1.015(1.001-1.030)$ & 0.046 & - & 0.408 \\
\hline
\end{tabular}

Factors with statistical significance from the results of univariate analysis were included in the logistic regression model as covariates. Adjustments were made for the following confounders: hypertension, diabetes, and hemoglobin. Multivariate analysis found T $\beta 4$, SOFA, and BMI to be the independent risk factors for AKI in patients with sepsis. The adjusted OR of T $\beta 4$ was $0.872(95 \% \mathrm{Cl}, 0.792-0.961)$. The adjusted OR of SOFA was $1.392(95 \% \mathrm{Cl}, 1.155-1.676)$. The adjusted OR of $\mathrm{BMI}$ was $1.218(95 \% \mathrm{Cl}$, 1.009-1.491). (Table 2)

\subsection{The clinical role of T $\beta 4$, SOFA, and BMI in the prediction of septic AKI occurrence}

ROC curve analysis was performed in order to determine the performance of T $\beta 4$, SOFA, BMI, and combinations of T $\beta 4$, SOFA, and BMI in the prediction of septic AKI (Fig. 2). 
The AUC of T $\beta 4$ was 0.746 , best cut off of T $\beta 4$ was 5.247 with sensitivity of $76.6 \%$ and specificity of $68.6 \%$. The AUC of SOFA was 0.727 , best cut off of SOFA was 9 with sensitivity of $55.3 \%$ and specificity of $82.4 \%$. The AUC of BMI was 683 , best cut off of BMI was 21.58 with sensitivity of $78.7 \%$ and specificity of $58.8 \%$. Interestingly, the combination of $T \beta 4$, SOFA, and BMI presented an AUC of 0.852 ( $P$ value $<0.001$ ) for septic AKI (Table 3 ).

Table 3

ROC curve of variables in the prediction of septic AKI

\begin{tabular}{|c|c|c|c|c|c|}
\hline Factor & AUC & $P$ value & Best cut off & Sensitivity & Specificity \\
\hline $\mathrm{T} \beta 4$ & 0.746 & $\otimes 0.001$ & 5.247 & 0.766 & 0.686 \\
\hline SOFA & 0.727 & $\otimes 0.001$ & 9 & 0.553 & 0.824 \\
\hline BMI & 0.683 & 0.002 & 21.58 & 0.787 & 0.588 \\
\hline Combination of $\mathrm{T} \beta 4$, SOFA and BMI & 0.852 & $₫ 0.001$ & - & - & - \\
\hline
\end{tabular}

To further elucidate the effects of T $\beta 4$ in septic AKI, we designed this animal experiment. The serum creatinine increased significantly in the sepsis model group compared to that of the NC group at 24 hours. In addition, the increased serum creatinine was significantly improved with T $\beta 4$ pretreatment (Fig. 3. A). Inflammatory infiltration and vacuolization in tubules were showed in the kidney tissue with LPS injection using H\&E-stain. The histopathological changes were ameliorated by $T \beta 4$ pretreatment (Fig. 3. B). For analysis of apoptosis of the kidneys, TUNEL assay was performed in the kidney tissue of the mice. The apoptosis percentage was also decreased with TB4 pretreatment (Fig. 3. C). In addition, T $\beta 4$ could inhibit the activation of Caspase-3 and slow down the inactivation of BCL-2 (Fig. 3. D).

\subsection{Tß4 prevents the LPS-induced activation of NF-KB and the induction of proinflammatory cytokines}

The levels of plasma IL-1 $\beta$, IL-6, and TNF- $a$ were significantly increased after LPS injection, and these effects was markedly reduced with $T \beta 4$ pretreatment (Fig. 4. A).

To explore the mechanism of regulating inflammatory cytokines, the effects of T $\beta 4$ on NF-KB pathway, an essential step for the activation of Kupffer cells and the production of proinflammatory cytokines, were studied. T $\beta 4$ significantly blocked the activation of the NF-KB pathway with respect to regarding the level of P-P65. These changes were also concomitantly associated with a change in the P-IKBa (Fig. 4. B).

\section{Discussion}


This study revealed the proportion of septic patients developing AKI in ICU to be $48 \%$. The development of AKI could significantly increase the mortality of patients with sepsis, and the risk of death increased with the grade of AKI. Multivariate regression analysis revealed T $\beta 4$, SOFA, and BMI at ICU admission to be independent risk factors for AKI in ICU patients with sepsis. In addition, Tß4, SOFA, and BMI at ICU admission can predict the occurrence of AKI in patients with sepsis. The ROC curve curve showed T $\beta 4$, SOFA, and BMI to be reliable in the prediction of septic AKI. Besides, this study proved that exogenous $T \beta 4$ could not only improves renal function and reduce renal apoptosis, but also reduces inflammatory factors by down-regulating the activity of NF-KB pathway so as to improve the systemic inflammatory response of sepsis model mice.

Related studies have shown T $\beta 4$ reduces kidney injury by reducing inflammatory reaction and oxidative stress[17]. In sepsis patients, T $\beta 4$ decreased significantly[18], leading to changes in the podocyte distribution within the glomerulus, increased periglomerular macrophage accumulation, and enhanced fibrosis, which results in progressive deterioration of renal function[19]. A study of 184875 people showed that the prognostic accuracy of the SOFA score was superior to SIRS criteria and qSOFA score among patients with suspected infection admitted to the ICU[20]. SOFA score combined with biomarkers have shown favorable results in predicting the development of septic AKI[21]. In addition, high BMI has been proven to be an independent risk factor for AKI in ICU patients. Obesity can cause some hemodynamic changes in the glomerulus, which will lead to glomerular injury. Furthermore, increased oxidative stress in obese patients can contribute to detrimental changes in the glomeruli[22].

In animal studies, exogenous $T \beta 4$ were reported beneficial effects in diverse pathologies including myocardial infarction[23], stroke[24], dry eye[25], and inflammatory lung disease[26]. Clinical studies also assessed the efficacy of T $\beta 4$ treatment in wound healing and cardioprotection[27]. Furthermore, exogenous T $\beta 4$ demonstrated good therapeutic effect in the experimental model of kidney disease, such as reducing proteinuria, albumin to creatinine ratio, plasma creatinine, blood urea nitrogen, and creatinine clearance rate[8]. This study proved that exogenous $T \beta 4$ could reduce renal apoptosis and attenuate renal dysfunction in septic mice. In addition, it was also demonstrated that T $\beta 4$ could reduce systemic inflammatory response through the prevention of the activation of the NF-KB pathway, which was similar to previous study [28].

Our study has several limitations. First, we didn't assessed factors of drug-induced kidney dysfunction. Second, the long-term outcome of patients was not followed up, especially the incidence of chronic kidney disease. Third, the effect of endogenous T $\beta 4$ in animal model of septic AKI can not be ruled out.

\section{Conclusions}

In general, AKI is a common complication in patients with sepsis, which worsened the outcome. The prediction model of T $\beta 4$ combined with SOFA and BMI can be used for prediction of the risk of septic AKI. Furthermore, exogenous T $\beta 4$ can protect renal function and reduce inflammatory reaction in the sepsis mice model, which may be developed as a promising potential drug against septic AKI. 


\section{Abbreviations}

ICU

Intensive care units;

AKI

Acute kidney injury;

$T \beta 4$

Thymosin beta-4;

LPS

Lipopolysaccharide;

BMI

Body mass index;

SOFA

Sequential Organ Failure Assessment score;

IL-1 $\beta$

Interleukin-1 $\beta$;

IL-6

Interleukin-6;

TNF-a

Tumor necrosis factor-a;

OR

Odds ratio;

ROC

Receiver-operating characteristic

AUC

Area under the curve

$\mathrm{Cl}$

Confidence interval;

\section{Declarations}

\section{Statements}

\section{Statement of EthicsConsent for publication}

All procedures performed in studies involving human participants were in accordance with the ethical standards of the institutional and/or national research committee and with the 1964 Helsinki Declaration and its later amendments or comparable ethical standards. The study was approved by the Bioethics Committee of the Ethic Committee of Zhongnan Hospital of Wuhan University (No. 2017004). All animal performed procedures were previously reviewed and approved by the Animal Care and Use Committee of 
Wuhan University and carried out according to the recommendations in the guide for the care and use of laboratory animals (No. 2018024).

Consent for publication Not applicable.

Availability of data and materials All data generated or analysed during this study are included in this published article [and its supplementary information files].

Conflict of Interest Statement: The authors declare that they have no competing interests.

\section{Funding Sources}

This work was supported by the National Natural Science Foundation (grants 81772046 and 81971816 to Dr Peng) and the Special Project for Significant New Drug Research and Development in the Major National Science and Technology Projects of China (2020ZX09201007 to Dr Peng).

\section{Authors' contributions}

Conceived the project, designed the project, analyzed data, and drafted the manuscript: J.Z., M.H., and Z.S. Extract and analyzed data: C.Y., X.J., and L.H. Designed the project, edited the manuscript and approved the final version: J.S., and Z.P.

Acknowledgment: Not applicable.

\section{References}

1. Rello J, Valenzuela-Sanchez F, Ruiz-Rodriguez M, Moyano S. Sepsis. A Review of Advances in Management. Adv Ther. 2017;34(11):2393-411. doi:10.1007/s12325-017-0622-8.

2. Cecconi M, Evans L, Levy M, Rhodes A. Sepsis and septic shock. Lancet. 2018;392(10141):75-87. doi:10.1016/S0140-6736(18)30696-2.

3. Koeze J, Keus F, Dieperink W, van der Horst IC, Zijlstra JG, van Meurs M. Incidence, timing and outcome of AKI in critically ill patients varies with the definition used and the addition of urine output criteria. BMC Nephrol. 2017;18(1):70. doi:10.1186/s12882-017-0487-8.

4. Panich T, Chancharoenthana W, Somparn P, Issara-Amphorn J, Hirankarn N, Leelahavanichkul A. Urinary exosomal activating transcriptional factor 3 as the early diagnostic biomarker for sepsisinduced acute kidney injury. BMC Nephrol. 2017;18(1):10. doi:10.1186/s12882-016-0415-3.

5. Khwaja A. KDIGO clinical practice guidelines for acute kidney injury. Nephron Clin Pract. 2012;120(4):c179-84. doi:10.1159/000339789.

6. Vanmassenhove J, Kielstein J, Jorres A, Biesen WV. Management of patients at risk of acute kidney injury. Lancet. 2017;389(10084):2139-51. doi:10.1016/S0140-6736(17)31329-6.

7. Pereira BJ, Barreto S, Gentil T, Assis LS, Soeiro EM, Castro I, et al. Risk factors for the progression of chronic kidney disease after acute kidney injury. J Bras Nefrol. 2017;39(3):239-45. 
doi:10.5935/0101-2800.20170041.

8. Vasilopoulou E, Riley PR, Long DA. Thymosin-beta4: A key modifier of renal disease. Expert Opin Biol Ther. 2018;18(sup1):185-92. doi:10.1080/14712598.2018.1473371.

9. Bollini S, Riley PR, Smart N. Thymosin beta4: multiple functions in protection, repair and regeneration of the mammalian heart. Expert Opin Biol Ther. 2015;15(Suppl 1):163-74.

doi:10.1517/14712598.2015.1022526.

10. Dunn SP, Heidemann DG, Chow CY, Crockford D, Turjman N, Angel J, et al. Treatment of chronic nonhealing neurotrophic corneal epithelial defects with thymosin beta 4. Arch Ophthalmol. 2010;128(5):636-8. doi:10.1001/archophthalmol.2010.53.

11. Gupta S, Kumar S, Sopko N, Qin Y, Wei C, Kim IK. Thymosin beta4 and cardiac protection: implication in inflammation and fibrosis. Ann N Y Acad Sci. 2012;1269:84-91. doi:10.1111/j.17496632.2012.06752.x.

12. Kleinman HK, Sosne G. Thymosin beta4 Promotes Dermal Healing. Vitam Horm. 2016;102:251-75. doi:10.1016/bs.vh.2016.04.005.

13. Sosne G, Kleinman HK. Primary Mechanisms of Thymosin beta4 Repair Activity in Dry Eye Disorders and Other Tissue Injuries. Invest Ophthalmol Vis Sci. 2015;56(9):5110-7. doi:10.1167/iovs.1516890.

14. Sosne G, Qiu P, Kurpakus-Wheater M. Thymosin beta 4: A novel corneal wound healing and antiinflammatory agent. Clin Ophthalmol. 2007;1(3):201-7.

15. Belsky JB, Morris DC, Bouchebl R, Filbin MR, Bobbitt KR, Jaehne AK, et al. Plasma levels of F-actin and $\mathrm{F}: \mathrm{G}$-actin ratio as potential new biomarkers in patients with septic shock. Biomarkers. 2016;21(2):180-5. doi:10.3109/1354750X.2015.1126646.

16. Edmonston DL, Pun PH. Coronary artery disease in chronic kidney disease: highlights from a Kidney Disease: Improving Global Outcomes (KDIGO) Controversies Conference. Kidney Int. 2020;97(4):6424. doi:10.1016/j.kint.2019.12.010.

17. Aksu U, Yaman OM, Guner I, Guntas G, Sonmez F, Tanriverdi G, et al. The Protective Effects of Thymosin-beta-4 in a Rat Model of Ischemic Acute Kidney Injury. J Invest Surg. 2019:1-9. doi:10.1080/08941939.2019.1672841.

18. Badamchian M, Fagarasan MO, Danner RL, Suffredini AF, Damavandy H, Goldstein AL. Thymosin beta(4) reduces lethality and down-regulates inflammatory mediators in endotoxin-induced septic shock. Int Immunopharmacol. 2003;3(8):1225-33. doi:10.1016/S1567-5769(03)00024-9.

19. Vasilopoulou E, Kolatsi-Joannou M, Lindenmeyer MT, White KE, Robson MG, Cohen CD, et al. Loss of endogenous thymosin beta4 accelerates glomerular disease. Kidney Int. 2016;90(5):1056-70. doi:10.1016/j.kint.2016.06.032.

20. Raith EP, Udy AA, Bailey M, McGloughlin S, Maclsaac C, Bellomo R, et al. Prognostic Accuracy of the SOFA Score, SIRS Criteria, and qSOFA Score for In-Hospital Mortality Among Adults With Suspected Infection Admitted to the Intensive Care Unit. JAMA. 2017;317(3):290-300. doi:10.1001/jama.2016.20328. 
21. Lee CW, Kou HW, Chou HS, Chou HH, Huang SF, Chang CH, et al. A combination of SOFA score and biomarkers gives a better prediction of septic AKI and in-hospital mortality in critically ill surgical patients: a pilot study. World J Emerg Surg. 2018;13:41. doi:10.1186/s13017-018-0202-5.

22. Ju S, Lee TW, Yoo JW, Lee SJ, Cho YJ, Jeong YY, et al. Body Mass Index as a Predictor of Acute Kidney Injury in Critically III Patients: A Retrospective Single-Center Study. Tuberc Respir Dis (Seoul). 2018;81(4):311-8. doi:10.4046/trd.2017.0081.

23. Smart N, Bollini S, Dube KN, Vieira JM, Zhou B, Davidson S, et al. De novo cardiomyocytes from within the activated adult heart after injury. Nature. 2011;474(7353):640-4. doi:10.1038/nature10188.

24. Morris DC, Cui Y, Cheung WL, Lu M, Zhang L, Zhang ZG, et al. A dose-response study of thymosin beta4 for the treatment of acute stroke. J Neurol Sci. 2014;345(1-2):61-7. doi:10.1016/j.jns.2014.07.006.

25. Sosne G, Qiu P, Ousler GW 3rd, Dunn SP, Crockford D. Thymosin beta4: a potential novel dry eye therapy. Ann N Y Acad Sci. 2012;1270:45-50. doi:10.1111/j.1749-6632.2012.06682.x.

26. Conte E, Genovese T, Gili E, Esposito E, lemmolo M, Fruciano M, et al. Thymosin beta4 protects C57BL/6 mice from bleomycin-induced damage in the lung. Eur J Clin Invest. 2013;43(3):309-15. doi:10.1111/eci.12048.

27. Goldstein AL, Hannappel E, Sosne G, Kleinman HK. Thymosin beta4: a multi-functional regenerative peptide. Basic properties and clinical applications. Expert Opin Biol Ther. 2012;12(1):37-51. doi:10.1517/14712598.2012.634793.

28. Shah R, Reyes-Gordillo K, Cheng Y, Varatharajalu R, Ibrahim J, Lakshman MR. Thymosin beta4 Prevents Oxidative Stress, Inflammation, and Fibrosis in Ethanol- and LPS-Induced Liver Injury in Mice. Oxid Med Cell Longev. 2018;2018:9630175. doi:10.1155/2018/9630175.

\section{Figures}



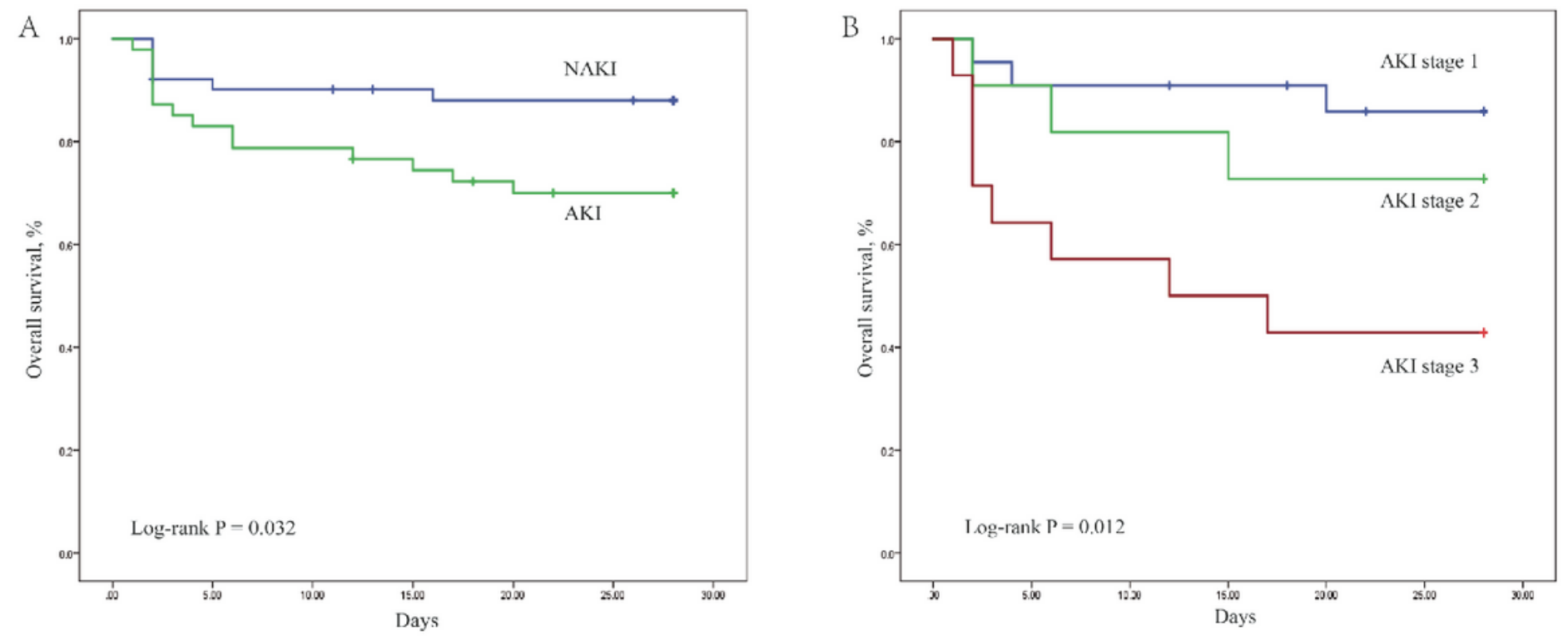

\section{Figure 1}

Kaplan-Meier survival curves. A Kaplan-Meier survival curves of AKI on overall survival in patients with sepsis. B Kaplan-Meier survival curves of AKI stage on survival in patients with septic AKI. 


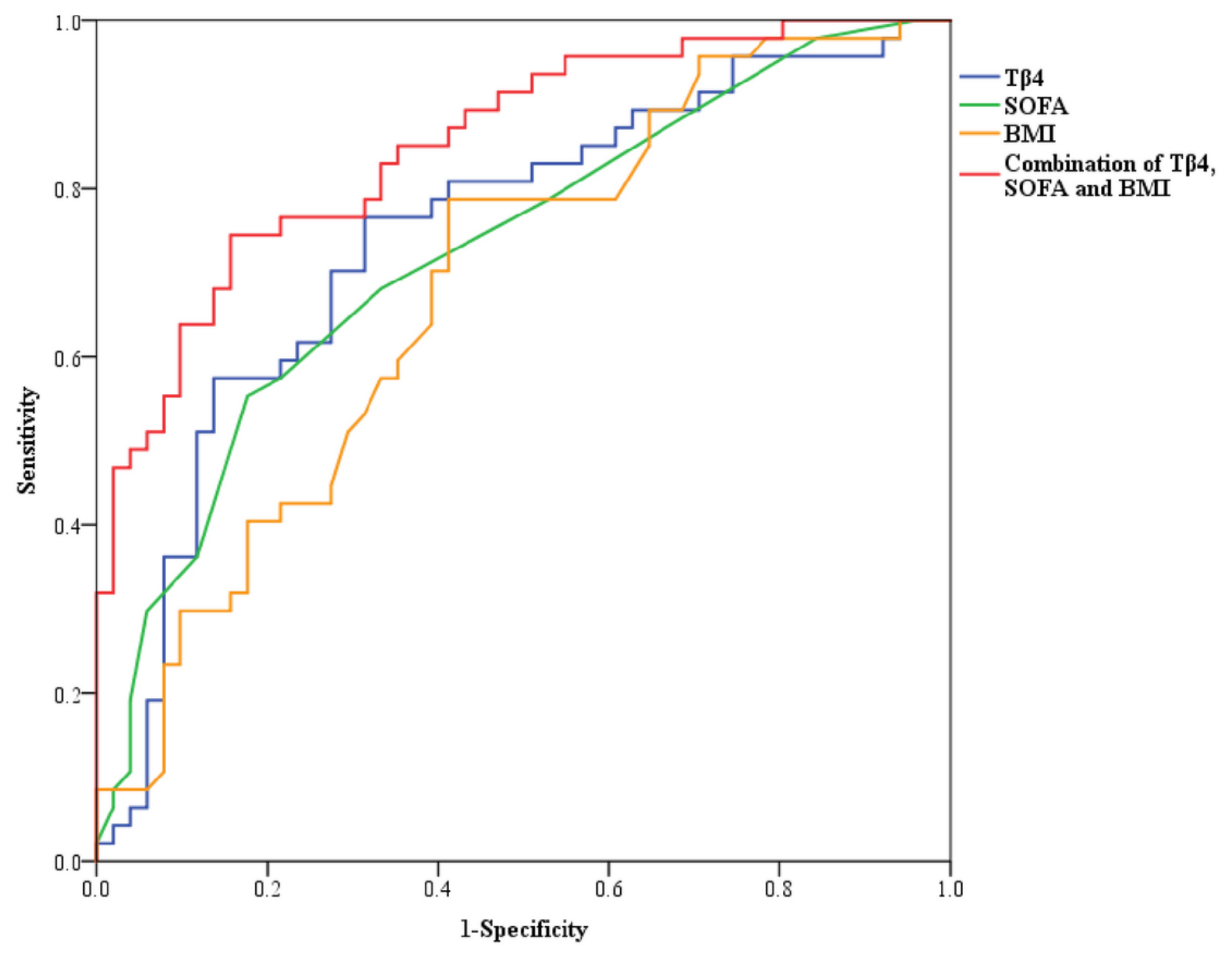

Figure 2

ROC curves of variables in predicting septic AKI. 
A

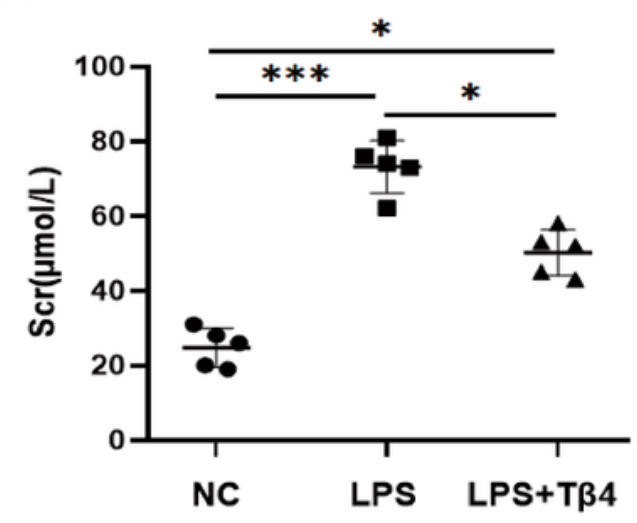

$\mathrm{C}$
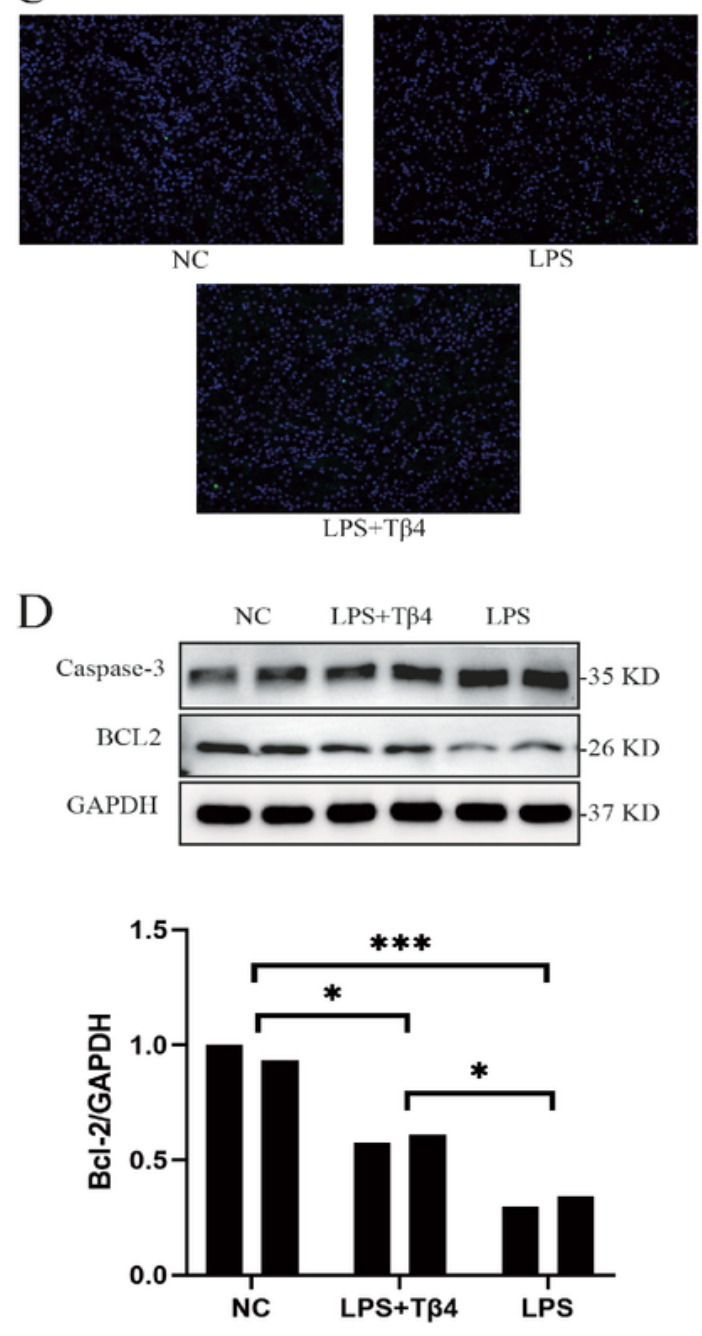

B
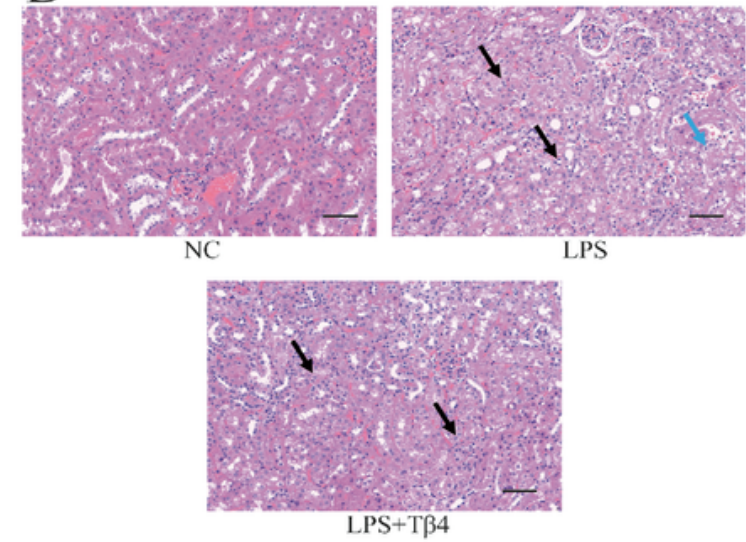

LPS
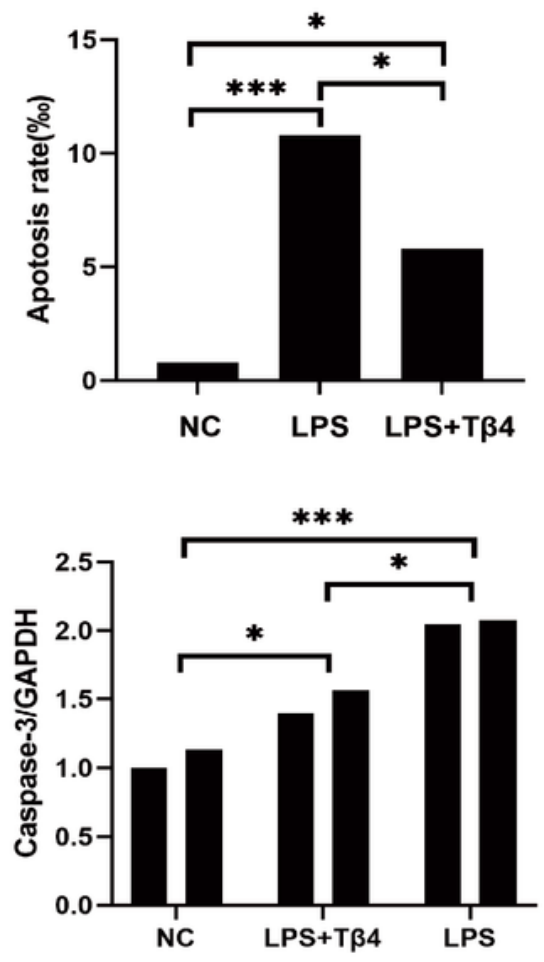

\section{Figure 3}

Exogenous T $\beta 4$ alleviated kidney injury in sepsis model. A. Serum creatinine was measured in each group to confirm the severity of AKI. B. H\&E staining of kidney sections in each group. Inflammatory infiltration and vacuolization in tubules were indicated in the insets by arrows. Bar represents $50 \mu \mathrm{m}$. C. Apoptosis rate was analysis by TUNEL in the kidney of mice. D. Western blot assay was utilized to detect apoptosis related protein expression in mice kidney. 
A
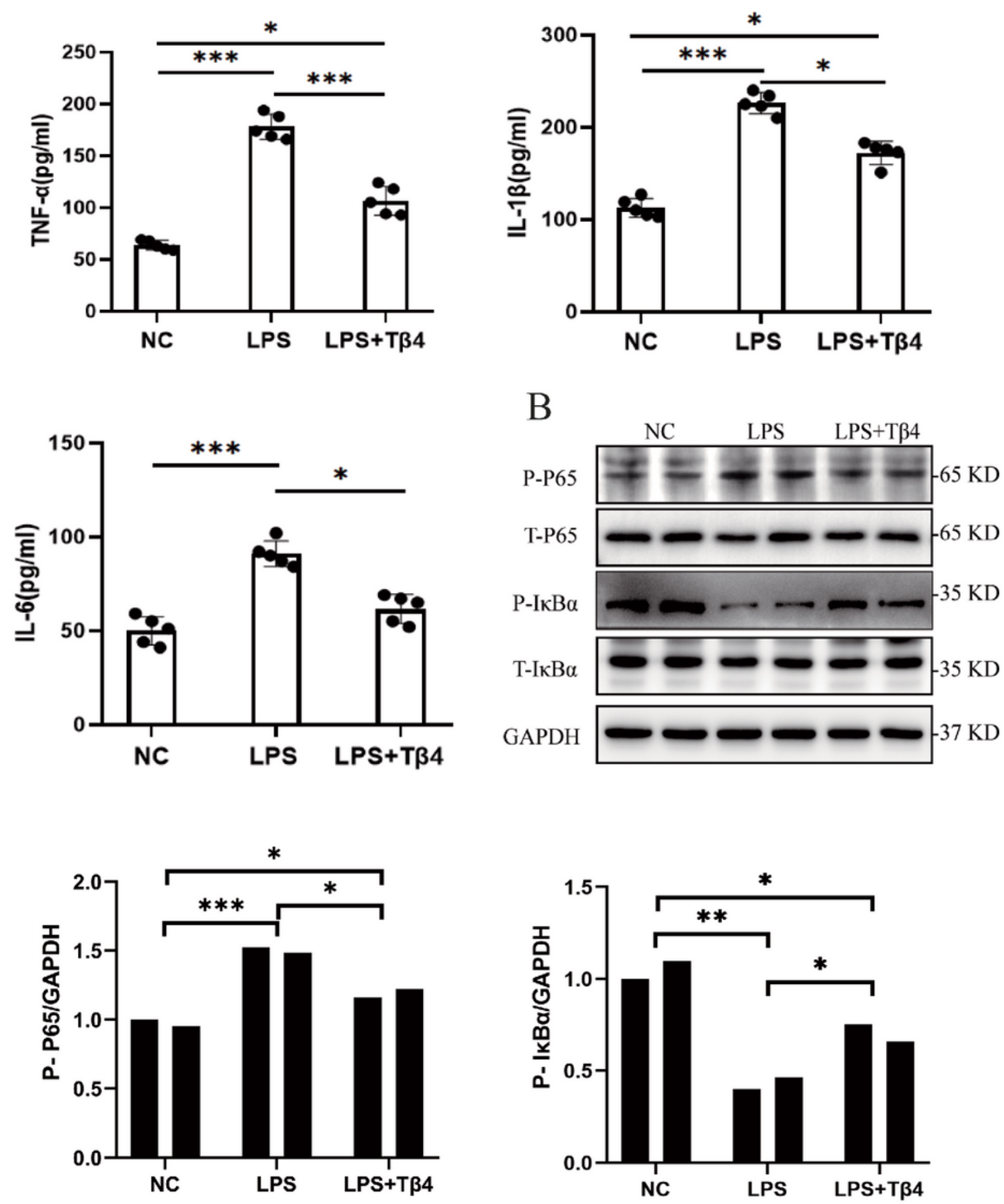

Figure 4

Exogenous T $\beta 4$ attenuated cytokine secretion via the NF-KB pathway. A. The cytokine TNF-a, IL-1 $\beta$, and IL-6 in the serum of mice were detected by ELISA. B. Western blot analysis of P-P65, T-P65, P-IKBa, and TIKBa protein expression in mice kidney tissues. Protein levels were determined after normalization to GAPDH. 